\title{
Representaciones sociales de la crisis ambiental en futuros profesores de química*
}

\author{
Social representations of the environmental crisis, \\ in preservice chemistry teachers
}

Yair Alexander Porras Contreras ${ }^{1}$

\begin{abstract}
Resumen: La crisis ambiental, como crisis civilizatoria, emerge de las interacciones poco efectivas entre los subsistemas biofísicos, sociales y culturales, constituyéndose en un riesgo global que trasciende el dominio material, para posicionarse en una categoría que involucra el significado y el sentido de la realidad. De esta manera, las ideas, creencias y concepciones que elaboran los profesores en formación inicial sobre la crisis ambiental, se convierten en derroteros desde los cuales se construye su saber pedagógico y su praxis educativa en relación con el ambiente. El propósito del presente artículo consiste en reconocer las representaciones sociales de la crisis ambiental, que circulan en un grupo de profesores en formación inicial de la Licenciatura en Química de la Universidad Pedagógica Nacional de Colombia (UPN), tomando como referente el enfoque estructural de la representación social.
\end{abstract}

Palabras-clave: Representación social. Crisis ambiental. Construcción social. Ambiente.

Abstract: The environmental crisis as a crisis of civilization emerges from the ineffective interactions between biophysical, social and cultural subsystems, becoming a global risk that transcends the material domain, to be positioned in a category that involves meaning and sense of reality. Ideas, beliefs and concepts that are developed by preservice teachers on the environmental crisis, become paths on which their pedagogical knowledge and educational practice in relation to the built environment develops. The purpose of this article is to recognize the social representations of the environmental crisis, circulating in a group of preservice chemistry teachers at the National Pedagogical University of Colombia, taking as reference the structural approach of social representation.

Keywords: Social representation. Environmental crisis. Social construction. Environment.

\footnotetext{
${ }^{*}$ Este artículo presenta parte de los resultados obtenidos por el autor en el Doctorado en Innovación e Investigación en Didáctica. Universidad Nacional de Educación a Distancia (UNED).

${ }^{1}$ Universidad Pedagógica Nacional (UPN), Bogotá, Colombia. E-mail: <yairporras@gmail.com>
} 


\section{Introducción}

La popularización del significado de la palabra crisis, en occidente, como "peligro" y "oportunidad", podríamos decir que nace el 12 de abril de 1959, gracias al discurso del entonces Senador John F. Kennedy (1959, p. 3), en un contexto propicio para la reivindicación de las minorías: la Fundación de Escuelas Unificadas para Personas de Raza Negra en Indianápolis. Según Kennedy (1959, p. 3, traducción nuestra), "cuando se escribe en chino, la palabra 'crisis' se compone de dos caracteres: uno representa peligro y el otro representa oportunidad. Las señales de peligro están a nuestro alrededor". Vale la pena recordar que estas señales de peligro, en un período de la historia enmarcado por la Guerra Fría, fueron señalando el camino para la comprensión de la crisis global, aspecto que Kennedy reconoce al describir el papel de la educación en la formación de líderes, capaces de enfrentar las problemáticas globales, en un mundo cada vez más dinámico y complejo.

Este período postparadigmático, retomando a Bauman (2010), que marca un punto de bifurcación en la historia de la humanidad, señala la transición hacia un nuevo enfoque de la realidad social, en el que no se habla únicamente de certidumbres, seguridad en el control mundial, o de la supremacía del hombre sobre la naturaleza. Se trata, más bien, de establecer la necesidad de reflexionar sobre un nuevo tipo de sociedad, que responda a los cinco retos que enfrenta una segunda modernidad: "la globalización, la individualización, la revolución de los géneros, el subempleo y los riesgos globales" (BECK, 2009, p. 2). Entre los riesgos más complejos a los que se enfrenta la humanidad, se encuentra la crisis ambiental, que de acuerdo con algunos autores emerge de la crisis de la modernidad. Este período de cambios inició con la conciencia de la finitud de los recursos y con ella la génesis del "pensar ecológico" (BALLESTEROS, 1985), lo que conllevó a la creación de una conciencia sobre la crisis de civilización (LEFF, 2005), evidenciada con la resistencia y la denuncia de autores como Carson (1962), Goldsmith (1972) y Schumacher (1973). Dicha perspectiva contestataria fue refrendada con la creación del Club de Roma en 1968 y el lanzamiento del informe Meadows, realizado por el MIT, en 1972.

Para autores como Giddens (1995, p. 35) más allá de denominarse este período como posmoderno, debería llamarse "modernidad tardía" denotando la radicalización y mundialización de las características de la modernidad. De acuerdo con este sociólogo, la relación "oportunidad y peligro" podría guardar alguna relación proporcional con "la confianza y el riesgo". De hecho, en relación con la constitución de la confianza, Giddens afirma que es un fenómeno fundamental para la constitución de la personalidad, por cuanto denota un sentido primario de "seguridad ontológica", una especie de protección frente a amenazas y peligros de la vida diaria (GIDDENS, 1995, p. 36).

Queda claro que la transición entre lo moderno y lo posmoderno, involucra la movilización de valores que van desde el culto al hedonismo, el placer y el consumo, los cuales reconstruyen un ideario de individuo y sociedad. De esta misma manera, la desarticulación entre las esferas tecno-económica, política y cultural, refleja ciertas contradicciones que reconfiguran el papel de la sociedad contemporánea. Entre ellas, el pensar que con la posmodernidad se cierra la puerta al hiperconsumo que, por el contrario, encuentra su apoteosis con el derroche de información (redes sociales), tecnofactos, ocio, etc. Al respecto, Lipovetsky (2000, p. 85) señala que "la crisis de las sociedades modernas es ante todo cultural o espiritual", es decir que la crisis, propia de la transición modernidad-posmodernidad, invita a un consumo diferenciado, el cual pretende 
[...] la búsqueda de calidad de vida, pasión por la personalidad, sensibilidad ecologista, abandono de los grandes sistemas de sentido, culto de la participación y la expresión, moda retro, rehabilitación de lo local, de lo regional, de determinadas creencias y prácticas tradicionales. (LIPOVETKY, 2000, p. 10).

Más allá de reconocer la transición modernidad-posmodernidad, como génesis de la crisis ambiental contemporánea, es conveniente dar claridad sobre el papel de la crisis ambiental en la comprensión del dominio material y el simbólico. De hecho, la racionalidad alternativa, con la que se adelanta una crítica profunda tanto a la cosificación del mundo, al principio de finitud de los recursos, a la obsolescencia programada y a la racionalidad instrumental, deriva en una racionalidad ambiental que va más allá de algunos principios filosóficos o epistemológicos, para contribuir a nuevas prácticas sociales, que tienen en su núcleo la emancipación y la descolonización del saber (LEFF, 2004).

Coincidimos con Agoglia (2010) cuando sostiene que la crisis ambiental es también el resultado de la racionalidad instrumental y sus causas están relacionadas con ciertos ideales de la Ilustración, asociados con el desarrollo industrial y el progreso científico y tecnológico. La crisis ambiental contemporánea deriva de una apropiación de los recursos con el objeto de marcar una transición entre las fuentes de energía, que emergen de los procesos fotosintéticos para concentrarse en los derivados fósiles. Este hecho marca un cambio paradigmático al reconocerse la variabilidad de los ritmos propios de los ciclos de la naturaleza (biogeoquímicos) y los ritmos de la producción humana (modelo de desarrollo en consonancia con las fuerzas productivas). (TOMASSINO; FOLADORI; TAKS, 2005).

La formación ambiental de los profesores no es ajena a estas polémicas, por lo que el reconocimiento de las representaciones sociales de la crisis ambiental desde una mirada compleja, permite identificar algunas visiones de mundo compartidas por los futuros profesores de Química, las cuales demuestran posturas epistemológicas, ontológicas, pedagógicas, éticas, políticas y ambientales, con las cuales es evidente su rol social y su papel preponderante en la construcción de significados sobre las realidades ambientales. De esta manera, el compromiso del profesorado en el reconocimiento y tratamiento pedagógico de la crisis ambiental, se convierte en un derrotero para consolidar una cultura ambiental que valore y resignifique el patrimonio cultural y biodiverso del país, así como la consolidación de una ciudadanía ambientalmente responsable y crítica. Dichos asuntos requieren un abordaje desde los programas de formación profesoral y la incorporación de la dimensión ambiental en la vida universitaria.

\section{La construcción social de la crisis ambiental}

Múltiples ideas y concepciones sobre la crisis ambiental vienen elaborándose en la actualidad, las cuales obedecen a diversas perspectivas sociales, culturales, políticas, económicas y educativas, que se constituyen en un conjunto de creencias y representaciones sociales, que funcionan como marcos de interpretación de la realidad. Tomando como referencia el análisis de Eder (1996), en relación con la comprensión de la relación naturaleza y sociedad, aparecen dos posiciones antagónicas sobre la crisis ambiental. Para algunos académicos (LEAKEY; LEWIN, 1997; RAUP, 1991) la primera postura establecería que la crisis ambiental hace parte 
de un devenir natural, en el que los procesos de dominación del hombre sobre el medio serían sólo un síntoma de la inercia de la misma evolución de la naturaleza. Otros autores (AGOGLIA, 2009; LEZAMA, 2004; PORRAS, 2014a) opinan que la crisis ambiental se constituye en una construcción social, un proceso dinámico producto de la evolución de la sociedad, en el que las representaciones sociales, las reglas y normas que se acuerdan o se imponen y la construcción socio-simbólica de la misma crisis, hacen parte del campo ambiental.

La crisis ambiental, que algunos científicos atribuyen a la salida de la población humana de los ecosistemas naturales y la implementación de la agricultura, hace ya 10.000 años (ELDREDGE, 2001), nos ha servido para redefinir lo que somos y, particularmente, la manera en que encajamos ecológicamente en el mundo:

Seguimos siendo parte del mundo natural, a pesar de la relación completamente nueva que hemos establecido con él. Esta relación es claramente una calle de doble dirección. Como ya hemos visto, es el impacto de la humanidad, con nuestra población enorme y siempre creciente, lo que subyace tras la actual y creciente oleada de extinción que amenaza con envolver a los ecosistemas y las especies de la Tierra. (ELDREDGE, 2001, p. 197)

En la construcción social de la crisis ambiental, se reconoce el campo ambiental como un sistema de relaciones sociales, definido por la posesión y producción de una forma específica de capital simbólico. Es un espacio de juego, que funciona con ciertas estructuras históricamente constituidas, en las cuales existen instituciones específicas, reglas y leyes de funcionamiento propias. El campo de lo ambiental se caracterizaría por la existencia de un capital común y la lucha por su apropiación, considerando que es allí donde se entretejen una serie de relaciones objetivas de poder entre los individuos, constituyéndose en una práctica social pluriparadigmática (PORRAS, 2014b, p. 14). En este sentido, las dimensiones de ese poliedro llamado crisis ambiental, deben estudiarse en función de las relaciones de poder que se entretejen en el territorio al que pertenecen los grupos humanos. Esto explicaría el surgimiento de voces que propugnan la resistencia y la disidencia, amparadas por movimientos sociales que proclaman la justicia ambiental (SCHLOSBERG, 2013; WALKER; BULKELEY, 2006), el ecologismo de los pobres (MARTÍNEZ-ALIER, 2005), la alternativa de resistir y crear (AUBENAS; BENASAYAG, 2002), la resiliencia social (FUENTE, 2012) y la construcción de un proyecto político-pedagógico en torno a la educación ambiental y la ecociudadanía (SAUVÉ, 2014).

Compartimos con Gonzalez-Gaudiano (2003) el interés que debemos brindar a los procesos de educación ambiental para la formación de una ciudadanía ambientalmente responsable, capaz de afrontar la crisis ambiental, particularmente cuando se considera que:

[...] la educación para la ciudadanía ambiental debe estar enmarcada dentro de una política ambiental y cultural; esto es, debe verse como un proceso donde la formación de ciudadanos fecunda la gestación de relaciones apropiadas entre nosotros y con el medio, dentro de un entramado complejo y a menudo, como ya vimos, contradictorio de representaciones e imágenes... (GONZALEZ-GAUDIANO, 2003, p. 614) 
En este sentido, una temprana aproximación a la definición de la crisis ambiental es la formulada por Guerasimov (1983), en la cual plantea algunos elementos que configuran la relación entre el hombre y el medio natural, haciendo énfasis en la degradación y el paulatino empeoramiento de las condiciones de vida en la Tierra:

El problema ecológico suele comprender: el empeoramiento cualitativo del entorno del hombre causado por la industrialización y la urbanización de su modo de vida, por el agotamiento de los recursos de energía y materias primas tradicionales (de relativo fácil acceso), el aumento continuo de presión demográfica sobre la naturaleza, el desequilibrio de los balances ecológicos naturales (mecanismos internos de autorregulación de la biosfera), el llamado exterminio 'económico' de algunas especies animales y plantas y las consecuencias genéticas negativas de la contaminación de la naturaleza con los desechos de la actividad económica de los hombres, incluyendo el peligro de degeneración genética del propio hombre. (GUERASIMOV, 1983, p. 3)

\section{Representaciones sociales}

Las representaciones sociales constituyen un concepto polisémico, una categoría $p l u$ riparadigmática (PÉREZ; PORRAS, 2005), en la cual confluyen diversos marcos interpretativos de la realidad, que les permiten a las personas evaluar y construir explicaciones, a través de los procesos comunicativos y de interacción social (PÉREZ; PORRAS; GUZMÁN, 2013). De hecho, las representaciones sociales revalidan la construcción social del conocimiento, un corpus específico con el cual la gente se desenvuelve, organiza su vida y toma decisiones. De acuerdo con Moscovici (1979, p. 18), "la representación es un corpus organizado de conocimientos y una de las actividades psíquicas gracias a las cuales los hombres hacen inteligible la realidad física y social, se integran en un grupo o en una relación cotidiana de intercambios, liberan los poderes de su imaginación".

Autores como Robert Farr (1984), reconocen las representaciones sociales como un modelo esquemático, que emerge cuando los individuos debaten temas de interés mutuo o cuando se comentan hechos significativos, producto de la incidencia de los medios de comunicación. Adicionalmente, el autor establece que las representaciones sociales tienen una doble función: "hacer que lo extraño resulte familiar y lo invisible perceptible", señalando que las representaciones sociales son:

[...] sistemas cognoscitivos con una lógica y un lenguaje propios. No representan simplemente "opiniones acerca de", "imágenes de", o "actitudes hacia" sino "teorías o ramas del conocimiento" con derechos propios para el descubrimiento y la organización de la realidad. Sistemas de valores, ideas y prácticas con una función doble: primero, establecer un orden que permita a los individuos orientarse en su mundo material y social y dominarlo; segundo, posibilitar la comunicación entre los miembros de una comunidad proporcionándoles un código para el intercambio social y un código para 
nombrar y clasificar sin ambigüedades los diversos aspectos de su mundo y de su historia individual y grupal. (FARR, 1984, p. 496)

Otra definición significativa de las representaciones sociales, es la que hace Banchs (1986) en su libro "Concepto de representaciones sociales", quien relaciona el impacto de los medios masivos de comunicación y algunos estereotipos de conducta modelada, reafirmados por valores colectivos, creencias y opiniones:

La forma de conocimiento del sentido común propio a las sociedades modernas bombardeadas constantemente de información a través de los medios de comunicación de masas [...] en sus contenidos encontramos sin dificultad la expresión de valores, actitudes, creencias y opiniones, cuya sustancia es regulada por las normas sociales de cada colectividad. Al abordarlas tal cual ellas se manifiestan en el discurso espontáneo, nos resultan de gran utilidad para comprender los significados, los símbolos y formas de interpretación que los seres humanos utilizan en el manejo de los objetos que pueblan su realidad inmediata. (BANCHS, 1986, p. 39)

Desde la perspectiva estructuralista, autores como Abric (1993) y Flament (2001) sostienen que las representaciones funcionan como sistemas de interpretación de la realidad que guían las relaciones de los individuos con su entorno físico y social, orientando, de esta manera, las acciones y las relaciones sociales. Según Abric (2001), dentro de las funciones clave de las representaciones sociales se encuentran: (a) permitir entender y explicar la realidad; (b) definir la identidad y permitir la salvaguarda de la especificidad de los grupos; (c) conducir los comportamientos y lasprácticas; (d) permitir justificar a posteriori las posturas y los comportamientos. A este autor se le reconoce haber sido uno de los primeros en establecer "la hipótesis del núcleo central de la representación", la cual establece que:

[...] la organización de una representación presenta una modalidad particular, específica: no únicamente los elementos de la representación son jerarquizados sino además toda representación está organizada alrededor de un núcleo central, constituido por uno o varios elementos que dan su significación a la representación. (ABRIC, 2001, p. 18)

Desde este enfoque, las representaciones sociales se organizan en función de un núcleo central y un sistema periférico. Al reconocerse el núcleo central, como un sistema en el que se construye la organización y el significado de la representación, se pretende evidenciar el carácter dinámico de las mismas. El ejercicio de movilizar una representación social, se hace más complejo al intentar transformar su núcleo central que se caracteriza por ser resistente al cambio, ya que contiene los elementos comunes al grupo social, particularmente la memoria colectiva. Así, los elementos periféricos más susceptibles al cambio, conectan el núcleo central con la realidad social. De ahí que las representaciones sociales tengan una doble función: cognitiva y de interacción social. Las funciones esenciales del núcleo central, según Guimelli (2001), son: (a) "generadora", ya que los elementos del núcleo central determinan si se crean o transforman los 
demás elementos de la representación; (b) “organizadora”, el sistema central determina los lazos e interacciones que se generen con los elementos periféricos. Estas características del núcleo central han permitido, en las últimas décadas, adelantar una serie de avances metodológicos para reconocer la centralidad de la representación, lo cual trasciende la dicotomía cuantitativo/ cualitativo, permitiendo avanzar en el estudio de las cogniciones centrales y periféricas.

Algunos estudios elaborados por la línea de investigación "Educación Ambiental en el Contexto Educativo Colombiano" de la Universidad Pedagógica Nacional (UPN), se centran en reconocer las representaciones sociales del ambiente (PÉREZ; PORRAS; GONZÁLEZ, 2007; PÉREZ et al., 2007), la educación ambiental y el campus universitario de docentes en formación, lo cual contribuye a la identificación de los marcos simbólicos, las prácticas discursivas y la construcción de significados, que emergen en la configuración de una cultura ambiental. La importancia de adelantar nuevos estudios sobre la estructura de las representaciones sociales de docentes en formación y en ejercicio, se centra en identificar algunas visiones de mundo compartidas, con las cuales se aprecian posturas epistemológicas, ontológicas, pedagógicas, éticas, políticas y ambientales de los futuros profesores. Esto permite comprender el rol social del profesorado y su incidencia en la construcción de significados acerca de las realidades ambientales en los diferentes contextos de interacción.

\section{Método}

Este estudio cualitativo, de corte descriptivo y exploratorio, se basa en el enfoque estructural de las representaciones sociales. Los participantes fueron 96 estudiantes de Licenciatura en Química de la Universidad Pedagógica Nacional de Colombia, 58 mujeres (60,41\%) y 38 hombres (39,59\%), en un rango de edad comprendido entre los 17 y 29 años. La distribución de estudiantes por semestres cursados, en el momento de diligenciar los instrumentos (segundo semestre de 2014), es la siguiente:

a) 37 estudiantes de cuarto semestre $(38,54 \%)$.

b) 16 estudiantes de sexto semestre $(16,66 \%)$.

c 27 estudiantes de octavo semestre $(28,12 \%)$.

d) 16 estudiantes de noveno semestre (16,66\%).

En la primera parte del estudio, el método utilizado para identificar los elementos centrales y periféricos de la representación social, fue el Análisis Prototípico y Categorial, desarrollado por Vergès (1992), a partir de la técnica de asociación libre de palabras. La estrategia consiste en solicitar a las personas la evocación de algunas palabras (usualmente entre 3 y 5 ), asociadas a un término inductor que es el objeto de la representación (DANY; URDAPILLETA; LO MONACO, 2014). En la presente investigación, se pide a los participantes que escriban 5 palabras que puedan ser equivalentes a "crisis ambiental", es decir, que puedan reemplazarla en una frase. Los indicadores que se tienen en cuenta para el análisis lexicográfico, son la frecuencia de palabras evocadas, que refleja su relevancia en el campo de representación y el rango de aparición, el cual determina si la palabra fue evocada en primer, segundo, tercer, cuarto o quinto lugar, constituyendo un indicador de la importancia del elemento para las personas.

Según Abric (2003, p. 64), a partir de la intersección entre la frecuencia media de evocación y el promedio de los rangos medios relevantes, se identifica un cuadro de doble entrada 
(Cuadro 1), con el que se evidencia la centralidad de los componentes de la representación, ligados al término inductor inicial, lo cual permite determinar la zona del núcleo central, la zona de contraste, la primera periferia y la segunda periferia.

Cuadro 1. Estructura de la representación social

\begin{tabular}{|c|c|c|c|}
\hline \multirow{4}{*}{$\begin{array}{l}\mathbf{F} \\
\mathbf{R} \\
\mathbf{E} \\
\mathbf{C} \\
\mathbf{U} \\
\mathbf{E} \\
\mathbf{N} \\
\mathbf{C} \\
\mathbf{I} \\
\mathbf{A}\end{array}$} & & \multicolumn{2}{|c|}{ RANGO } \\
\hline & & Bajo (Importancia alta) & Alto (Importancia Baja) \\
\hline & Alta & Núcleo Central $(++)$ & $\begin{array}{l}\text { Elementos de la } 1^{\text {a }} \\
\text { Periferia }(+-)\end{array}$ \\
\hline & Baja & Zona de Contraste $(-+)$ & $\begin{array}{l}\text { Elementos de la } 2^{\text {a }} \\
\text { Periferia (--) }\end{array}$ \\
\hline
\end{tabular}

Fuente: elaborado por el autor.

La estructura de la representación social, consta de un núcleo central conformado por las palabras que tienen una alta frecuencia y un bajo rango de aparición, por lo que se consideran las más importantes. La zona de contraste involucra las palabras con baja frecuencia y alta importancia (rango bajo). Según Abric (2003, p. 64), estas palabras de la zona de contraste, revelan "la existencia de subgrupos portadores de una representación diferente, cuyo núcleo estaría compuesto por uno o más elementos aquí presentes".

El sistema periférico está constituido por aquellos elementos que pueden modificarse en la representación, se caracterizan por tener un rango alto de evocación y por lo tanto, una importancia baja en el esquema representacional de los sujetos.

La segunda parte del estudio, consistió en un cuestionario de 8 preguntas en el que se solicitaba a los estudiantes responder preguntas relacionadas con la concepción de crisis ambiental, los ejemplos que podría enunciar de dicha crisis, a nivel local y/o global y las posibles causas de la misma. Las categorías de análisis construidas sobre las respuestas formuladas por los estudiantes, tomando como referencia el análisis prototípico, dieron como resultado cinco posibles representaciones de la crisis ambiental, las cuales involucran aspectos que trascienden lo material para posicionarse también en dominios de orden ético-moral, sociocultural, educativo y científico-tecnológico.

\section{Resultados y análisis}

\section{Análisis prototípico}

Los estudiantes que participaron en el estudio produjeron 450 palabras de las cuales 110 fueron distintas. En promedio, cada estudiante evocó entre 4 y 5 palabras. En una primera etapa del análisis de prototipicidad, propio de la estructura representacional de la crisis ambiental, se determinó una frecuencia mínima de evocación de 15 y un rango mínimo de 3. Posteriormente, 
en una segunda etapa, se obtiene un listado de las 24 palabras más importantes (Cuadro 2), las cuales nos indican una relación jerárquica con el objeto de representación.

Cuadro 2. Elementos constitutivos de la representación social de la crisis ambiental

\begin{tabular}{|l|l|l|l|l|l|l|l|}
\hline $\mathbf{1}$ & Contaminación & $\mathbf{2}$ & Daño del entorno & $\mathbf{3}$ & Deforestación & $\mathbf{4}$ & Problema \\
\hline $\mathbf{5}$ & Inconciencia & $\mathbf{6}$ & Deterioro & $\mathbf{7}$ & Escasez de recursos & $\mathbf{8}$ & Destrucción \\
\hline $\mathbf{9}$ & Falta de cultura & $\mathbf{1 0}$ & Impacto ambiental & $\mathbf{1 1}$ & Efecto invernadero & $\mathbf{1 2}$ & Extinción \\
\hline $\mathbf{1 3}$ & Desastres naturales & $\mathbf{1 4}$ & Calentamiento global & $\mathbf{1 5}$ & Consumismo & $\mathbf{1 6}$ & Degradación \\
\hline $\mathbf{1 7}$ & Caos & $\mathbf{1 8}$ & Catástrofe & $\mathbf{1 9}$ & Basura & $\mathbf{2 0}$ & Riesgo \\
\hline $\mathbf{2 1}$ & Muerte & $\mathbf{2 2}$ & Enfermedad & $\mathbf{2 3}$ & Desequilibrio & $\mathbf{2 4}$ & Polución \\
\hline
\end{tabular}

Fuente: elaborado por el autor.

Para el tratamiento de los datos recolectados, se utilizó el software EVOC/2003 (Ensemble de Programmes Permettant L'analyse des Évocations), el cual permitió desarrollar una organización de las palabras evocadas en función de su jerarquía, particularmente, la interacción entre la frecuencia media y el rango de aparición. En relación con la estructura de la representación social de la crisis ambiental, se construyó un cuadro de doble entrada (Cuadro 3) en el que se distribuyeron las 24 palabras con mayor frecuencia y rango de evocación.

Cuadro 3. Elementos de la representación social de la crisis ambiental

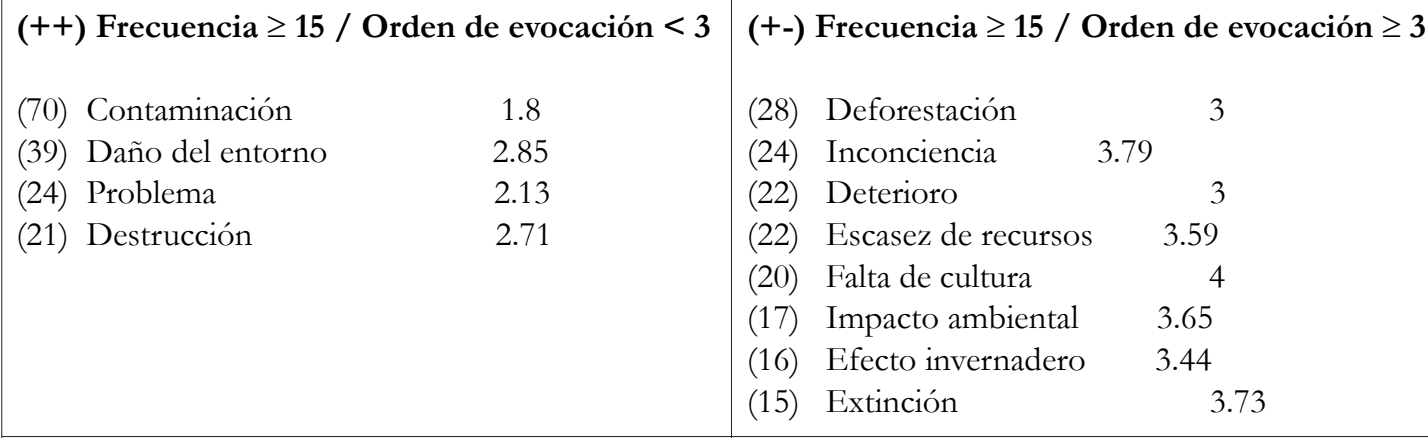

(-+) Frecuencia $<3$ / Orden de evocación $<3$

(--) Frecuencia $<3$ / Orden de evocación $\geq 3$

(11) Desastres naturales

2.18

2.36

(11) Calentamiento global

2.63

(8) Caos

2.43

(11) Consumismo

3.91

(10) Degradación

(8) Basura

3.29

(7) Catástrofe

(7) Riesgo

3.86

(7) Muerte

3.86

(6) Enfermedad

(6) Desequilibrio

3.5

(5) Polución

3.4

Fuente: elaborado por el autor. 
El núcleo central de la representación social de la crisis ambiental está formado por 4 palabras: contaminación, daño del entorno, problema y destrucción. Todas ellas hacen referencia al dominio material con el que las personas priorizan las evidencias de la crisis, reconociendo en el subsistema biofísico la base sobre la que se desarrollan los desequilibrios ambientales. En el núcleo representacional se destaca una visión naturalista y conservacionista del ambiente, la cual propugna una dicotomía entre la naturaleza y la sociedad, que según Descola (2012, p. 31), ratificaría un presupuesto de la modernidad: "la naturaleza sólo tiene sentido en oposición a las obras humanas, ya se prefiera dar a estas el nombre de "cultura", "sociedad" o "historia", en el lenguaje de la filosofía y las ciencias sociales, o bien de "espacio antropizado", "mediación técnica” o "ecúmene", en una terminología más especializada".

En la zona de contraste se encuentran otras palabras que guardan relación directa con el núcleo central de la crisis ambiental: desastres naturales, calentamiento global, caos y catástrofe. Estas denominaciones reflejan una mirada apocalíptica de la realidad ambiental, en la que los medios de comunicación, los informes de expertos y el llamado de activistas se constituyen en los referentes sobre los cuales se construyen las representaciones sociales de la crisis ambiental. Valdría la pena preguntarnos por el papel de los medios de comunicación en la configuración de la crisis ambiental, ya que la obsesión por el inmediatismo ha provocado que las tragedias ambientales se perciban como algo afín a las sociedades contemporáneas, hecho que se ratifica con un tratamiento superficial de las problemáticas ambientales y las catástrofes, sobrevalorando las descripciones de los hechos y brindándole poca importancia a la interpretación de los mismos.

En las zonas periféricas se ubican 2 tipos de denominaciones de la crisis ambiental: aquellos elementos que realzan el dominio materialista de la representación social (deforestación, deterioro, escasez de recursos, efecto invernadero, extinción) y los elementos que se categorizan en el dominio ético-moral (inconciencia, falta de cultura, impacto ambiental). Esta transición hacia un modelo de representación social material y simbólico, en el que se articulan elementos del subsistema biofísico y el subsistema sociocultural, mediados por valores, que si bien no son prioritarios en el esquema representacional de los estudiantes encuestados, denotan un escenario más reflexivo, propicio para que los procesos educativos se constituyan en ejes centrales a la hora de movilizar aquellas representaciones sociales poco solidarias con el ambiente.

\section{Análisis categorial}

A partir de las respuestas generadas por los profesores en formación inicial (96), al cuestionario "Ideas sobre la crisis ambiental", se establecieron 5 categorías de análisis (Cuadro 4), que condensan las representaciones sociales sobre dicha crisis:

Vale la pena anotar que algunas de las respuestas de los profesores pertenecen a diversas categorías, lo que prueba el carácter pluridimensional de la representación social. En este sentido, la perspectiva pluriparadigmática en el estudio de las representaciones sociales, consiste en el "establecimiento de una red de significación por parte de los sujetos, en un espacio relacional en el que las interacciones entre la pluralidad de paradigmas explicativos generados desde perspectivas distintas, funcionan como marcos de interpretación de la realidad" (PORRAS, 2005, p. 147). Esto quiere decir, que en la construcción social de la crisis ambiental existe una mediación 
Representaciones sociales de la crisis ambiental ...

Cuadro 4. Categorías en el estudio de las Representaciones Sociales de la Crisis Ambiental

\begin{tabular}{|l|c|c|}
\hline Categorías de la representación social de la crisis ambiental & $\begin{array}{c}\text { Número de } \\
\text { respuestas }\end{array}$ & $\begin{array}{c}\text { Porcentaje } \\
\mathbf{\%}\end{array}$ \\
\hline Dominio materialista (crisis antrópica) & 46 & 32.86 \\
\hline Dominio ético-moral (valores, conciencia) & 44 & 31.43 \\
\hline Dominio socio-cultural (económico y político) & 28 & 20 \\
\hline Dominio educativo (formación ambiental) & 16 & 11.43 \\
\hline Dominio científico y tecnológico (avance, impacto) & 6 & 4.28 \\
\hline Total & 140 & 100 \\
\hline
\end{tabular}

Fuente: elaborado por el autor.

entre diferentes dominios que funcionan como filtros de la realidad, los cuales promueven, a su vez, la articulación entre las posiciones de los individuos, las ofertas simbólicas del colectivo y las actitudes frente a la relación hombre-naturaleza. Una aproximación a los tipos de representaciones sociales que emergen en el grupo de futuros profesores, se presenta a continuación:

\section{- Representación social de la crisis ambiental desde el dominio materialista (crisis antrópica)}

Desde esta perspectiva, la crisis ambiental se concibe como un deterioro de las condiciones actuales, que dan paso a la escasez de los recursos y el empeoramiento de las condiciones de vida de las personas, bien sea por un agotamiento de los insumos básicos para la supervivencia de la especie, o por un decaimiento en la producción o mantenimiento de dichos recursos, en comparación con un estado de pre-crisis. Esta perspectiva, que ratifica el núcleo central de la representación social, nos lleva a pensar el ambiente como un escaparate lleno de recursos, entre los cuales los no renovables se constituyen en el motivo de preocupación. Dicha postura se ratifica con algunas ideas sobre la crisis ambiental, en las que prevalece la dicotomía naturaleza-sociedad y por ende, la atribución a la acción humana de las consecuencias de todos los desequilibrios ambientales, debido a su irrupción en una naturaleza ajena a su presencia:

La crisis ambiental es... la alteración del equilibrio en los ecosistemas. Contaminación de agua, suelos, aire, extinción de bosques, especies, alteración en la cadena trófica, por factores antropogénicos. [E25]

[...] significa daños, problemas, que se realizan en contra de la naturaleza. Afectación de bumedales, calentamiento global, deforestación. Los culpables somos todos los seres bumanos. [E33]

Como se puede apreciar, queda la imagen de la añoranza por un mundo sin restricciones al acceso de recursos, por lo que la crisis ambiental se convierte en "la metáfora de la expulsión 
del paraíso, [con la cual] [...] podemos explicar poéticamente el inicio de la separación entre naturaleza y cultura que ha caracterizado a occidente" (NOGUERA, 2004, p. 31).

\section{- Representación social de la crisis ambiental desde el dominio ético-moral (valores, conciencia)}

Parte del legado de la modernidad que ha desembocado en la génesis de la crisis ambiental, propugna la escisión entre la naturaleza y la sociedad, tomando como lema del progreso la utilización de una imagen del hombre como el centro del universo (antropocentrismo). Desde esta perspectiva, la supuesta superioridad del hombre sobre el resto de seres vivos, viene a ser criticada por un número significativo de estudiantes, los cuales alertan sobre la necesidad de promover la transición hacia una representación del planeta como interlocutor y no como escaparate:

La crisis ambiental es un desequilibrio ecosistémico, causado por el inico animal destructor de su medio, el ser humano, ya que su "racionalismo" lo ha usado de forma inadecuada y desmedida...por ejemplo en el desequilibrio climático por la destrucción de la capa de ozono y el aumento de albedo. [E28]

De igual modo, resulta interesante encontrar posiciones en las cuales se reclama una "nueva ética" en la que las personas y los demás seres de la naturaleza se consideren sujetos de derechos, por lo que se puede entrever en las afirmaciones de los futuros profesores, el acercamiento a ciertas características del biocentrismo:

La crisis ambiental es la alteración del entorno... a nivel global aquellos territorios hostiles donde se presentan guerras, donde los habitantes deben huirpara conservar sus vidas...se debe a la falta de respeto por los otros seres vivos y su entorno. [E12]

Estas ideas confirman la tesis de Burgui (2011, p. 33), en la que reconoce que "los biocentristas proponen extender la consideración de relevancia moral a todos los seres vivos". Por esta razón, es necesario reconocer el valor intrínseco de los llamados seres de la naturaleza y su importancia, más allá de convertirlos en valores materiales. Así, un llamado hacia el fortalecimiento de una conciencia social, como parte de los elementos propios de la periferia de la representación social, hacen pensar en la necesidad perentoria de fomentar una formación ambiental más solidaria con la vida: "La crisis se traduce en alteraciones de los ecosistemas. Mal manejo de residuos, contaminación por los medios de transporte, desperdicio de recurso hidrico. Se atribuye a la falta de conciencia social por el cuidado, prevención y reutilización de los recursos” [E23].

\section{- Representación social de la crisis ambiental desde el dominio socio-cultural (económico y político)}

Tomando como referentes los planteamientos de Leff (2002, 2004, 2010), en lo que a la racionalidad ambiental se refiere, la representación social de la crisis ambiental, desde el dominio sociocultural se explica por la construcción del conocimiento que hace apología a la 
transformación del mundo, amparada por paradigmas hostiles que mutilan el carácter complejo de la realidad, bajo el pretexto del desarrollo sostenible. Algunos estudiantes señalan como causas de la crisis ambiental, el desarrollo industrial, el hiperconsumo y una política de explotación de los recursos, que mina la identidad de los territorios:

[...] es un problema por el que atraviesa una sociedad...un ejemplo sería el agotamiento de combustibles fósiles, a nivel local la destrucción de fauna y flora. Se debe a actividades bumanas en pro del desarrollo industrial, económico y social. [E3]

[...] cuando el entorno es afectado negativamente por los mismos individuos que lo habitan, generando impactos. El efecto invernadero, los cambios climáticos, las sequías, la sobrepoblación, debido a las acciones incontroladas en favor del capitalismo y el consumo. [E16]

[...] se da por la máxima contaminación del planeta, debido a la deforestación, la industrialización, no reciclar, pues esta es la etapa más alta a la que ha llegado la industrialización para cubrir la demanda de la sobrepoblación. [E41]

En estas afirmaciones se ratifica la instalación de la crisis ambiental asociada a una crisis del conocimiento, lo que nos hace pensar en el riesgo de continuar con un modelo de desarrollo que pone a las personas al servicio de la economía. De esta manera, coincidimos con Leff (2007, p. 11) cuando afirma que la crisis ambiental

[...] es el signo de una nueva era histórica. Esta crisis civilizatoria es ante todo una crisis del conocimiento. La degradación ambiental es resultado de las formas de conocimiento a través de las cuales la humanidad ha construido el mundo y lo ha destruido por su pretensión de universalidad, generalidad y totalidad; por su objetivación y cosificación del mundo.

\section{- Representación social de la crisis ambiental desde el dominio educativo (formación ambiental)}

La educación ambiental como proceso de formación enfocado a la emancipación social e ideológica, que pretende reconocer las capacidades de las personas para incentivar el despliegue de talentos y potencialidades, se constituye en una alternativa fundamental a la hora de promover una cultura del compromiso frente a la vida, aspecto que reclaman los docentes en formación cuando atribuyen, como causa de la crisis ambiental, la falta de procesos educativos enfocados al estudio e investigación del ambiente:

La crisis ambiental es un cambio irregular en el territorio que afecta a toda la población. La contaminación de los ríos, el mal manejo de desechos, el consumismo, el efecto invernadero, la acidificación de mares, la pérdida de especies, se deben a la falta de educación sobre el valor de la vida. [E21] 
La crisis es una problemática producto de la contaminación que produce el hombre y se deposita en el ecosistema; es atribuible a la educación y la poca investigación que se genera en la enseñanza del ambiente, además de la inconciencia y la falta de cultura ciudadana. [E77]

[...] causa de problemáticas como el cambio climático, la venta de recursos (Zonas biológicamente ricas) a países globalizados para "curar" el impacto de sus industrias, falta de educación ambiental. [E96]

Habría que pensar en un proceso de enseñanza y aprendizaje en el que la complejidad, el caos y la indeterminación hagan parte del estudio de la crisis ambiental, hecho que confirma la necesidad de trascender la mirada moderna de un ser humano alejado del ambiente, para reconfigurar una ética ecociudadana, que además de denunciar los desequilibrios y las inequidades, promueva el desarrollo de valores sociales como el compromiso y la solidaridad. Para Sauvé (2014), la articulación entre la ética y la política constituye un asunto indisoluble, de ahí que

[...] el compromiso, particularmente el compromiso político, corresponde entre otros a un proyecto de emancipación: elegir su lugar de compromiso supone una afirmación identitaria - en ella la identidad política - y deviene un acto de esperanza; es posible romper la alienación y cambiar las cosas. (SAUVÉ, 2014, p. 21)

\section{- Representación social de la crisis ambiental desde el dominio científico y tecnológico (avance, impacto)}

Desde el dominio científico y tecnológico, la crisis ambiental se considera resultado de un cierto optimismo ingenuo, con el cual las personas atribuyen al avance tecno-científico, el progreso de las sociedades. De acuerdo con el profesor Angel-Maya (2003, p. 11), parece que de este optimismo tecnológico que supuestamente conduce al desarrollo, las personas pasan a un pesimismo desesperanzador, endilgándole al conocimiento científico y tecnológico, una responsabilidad exclusiva frente al estado ambiental del planeta:

La crisis se relaciona con los problemas de contaminación en todos los aspectos. A nivel global el efecto invernadero y local, la contaminación, por el mal manejo de residuos y la falta de conciencia por el abuso tecnológico. [E42]

[...] desequilibrio del ambiente, interrupción de procesos o ciclos, reacciones negativas que afectan a los seres vivos, por sobrepoblación y atribuible a los avances científicos y la no planeación del daño ambiental. [E61] 
Vale la pena destacar el carácter crítico que algunos profesores en formación inicial asumen, al considerar que parte de la crisis ambiental se debe, inclusive, al tipo de trabajo que se realiza con las sustancias químicas en los laboratorios de las instituciones educativas, por lo que la perspectiva de una ética ambiental parte de la reflexión sobre su propia praxis profesional: "[...] es el mal uso de las innovaciones tecnológicas, lo que produce daño y agotamiento de recursos. El mal uso de productos biodegradables, la utilización de sustancias químicas desechadas en el laboratorio, por la poca investigación y el mal uso de productos" [E49].

\section{Consideraciones finales}

La crisis ambiental se constituye en un riesgo complejo al cual se enfrenta la humanidad. Por esta razón, las representaciones sociales de la crisis ambiental están vinculadas a los imaginarios, los valores culturales compartidos, los aprendizajes y las prácticas sociales, que definen el comportamiento, la comprensión y las relaciones entre los seres humanos y el entorno. Reconocer cinco dominios o categorías sobre la crisis ambiental que elaboran profesores en formación inicial, reafirman el carácter polisémico, multicultural y pluriparadigmático en el que se construyen percepciones, ideas, creencias, concepciones y representaciones de la realidad ambiental. Estos resultados contribuyen a la identificación de los referentes simbólicos, la construcción de significados y prácticas que evidencian los futuros docentes de Química, al establecer una estrecha relación entre las formas de representarse el mundo y las acciones que se ejercen sobre el ambiente, aspectos que demandan un desafío para la educación, la formación de profesores y la construcción de una universidad ambientalmente sustentable.

Queda claro, a partir de los resultados de este estudio, que la crisis ambiental es en sí una crisis sistémica, que emerge de las interacciones poco efectivas entre los subsistemas biofísicos, sociales y culturales, esto significa desequilibrios entre diferentes niveles de complejidad que van más allá de carencias en los recursos. Es una crisis que trasciende el dominio material, para posicionarse en lo simbólico, el significado y el sentido de la realidad. Así, la crisis ambiental se relaciona directamente con la crisis de la identidad y con ella el incremento de problemáticas asociadas con el deterioro de la autoimagen, el autocuidado y la carencia de valores ambientales. Es también una crisis de la alteridad, que se refleja en la opresión, la falta de libertad, la poca solidaridad, la vulnerabilidad social, el racismo ambiental, la corrupción y las amenazas contra la salud. Es una crisis del territorio, que se evidencia con la pérdida de ese espacio donde se construye la relación social, situación que promueve la injusticia ambiental, la migración y la pobreza. La suma de estos desequilibrios afecta el ambiente, nuestro oikos, un sistema dinámico y complejo, que establece relaciones rizomáticas entre sus componentes (biofísicos, sociales y culturales). De esta manera, podríamos concluir que la crisis ambiental, es una crisis que involucra la identidad, la alteridad, la territorialidad y particularmente, la construcción del sujeto ecosocial. 


\section{Referencias}

ABRIC, J. C. Central system, peripheral system: their function and roles in the dynamic of social representations. Papers on Social Representations, Linz, v. 2, n. 2, p. 75-78, 1993.

. Prácticas sociales y representaciones. México: Ediciones Coyoacán, 2001.

. La recherche du noyau central et de la zone muette des représentations sociales. In:

ABRIC, J. C. Méthodes d'étude des représentations sociales. Paris: Eres, 2003. p. 59-80.

AGOGLIA, O. B. La crisis ambiental como un proceso: un análisis reflexivo sobre la emergencia, desarrollo y profundización desde la perspectiva de la teórica crítica. Tesis (Doctor en educación ambiental) - Universidad de Girona, Girona, 2010. Disponible en: <http://dugi-doc.udg.edu/handle/10256/4600>. Visitado el: 14 oct. 2014.

ÁNGEL-MAYA, A. La diosa Némesis: desarrollo sostenible o cambio cultural. Cali: Corporación Universitaria Autónoma de Occidente, 2003.

AUBENAS, F.; BENASAYAG, M. Résister, c’est créer. Paris: La Découverte, 2002.

BALLESTEROS, J. Hacia un modo de pensar ecológico. Anuario Filosófico, Pamplona, v. 18, n. 2, p. 169-176, 1985. Disponible en: <https://dialnet.unirioja.es/servlet/ articulo?codigo $=28797>$. Visitado el: 18 marzo 2016.

BANCHS, M. Concepto de representaciones sociales: análisis comparativo. Revista Costarricense de Psicología, San José, v. 89, p. 27-40, 1986.

BAUMAN, Z. La cultura en el mundo de la modernidad líquida. Buenos Aires: Fondo de Cultura Económica, 2010.

BECK, U. La sociedad del riesgo global. Madrid: Siglo XXI, 2009.

BURGUI, M. Ética medioambiental: responsabilidad y derechos. Madrid: Bubok, 2011.

CARSON, R. Silent spring. Boston: Houghton Mifflin, 1962.

DANY, L.; URDAPILLETA, I.; LO MONACO, G. Free associations and social representations: some reflections on rank-frequency and importance-frequency method. Quality \& Quantity, Dordrecht, v. 48, n. 2, p. 489-507, 2014.

DESCOLA, P. Más allá de naturaleza y cultura. Buenos Aires: Amorrortu, 2012.

EDER, K. The social construction of nature. London: Sage, 1996.

ELDREDGE, N. La vida en la cuerda floja: la humanidad y la crisis de la biodiversidad. Barcelona: Tusquets, 2001.

FARR, R. M. Las representaciones sociales. In: MOSCOVICI, S. (Comp.). Psicología social II. Barcelona: Paidós, 1984. p. 495-506.

FLAMENT, C. Pratiques sociales et dynamique des représentations. In: MOLINER, P. (Ed.). La dynamique des représentations sociales. Grenoble: PUG, 2001. p. 43-58. 
FUENTE, M. E. La comunalidad como base para la construcción de resiliencia social ante la crisis civilizatoria. Polis, Santiago, n. 33, p. 1-16, 2012. Disponible en: < http://polis.revues. org/8495>. Visitado el: 18 marzo 2016.

GIDDENS, A. et al. Las consecuencias perversas de la modernidad: modernidad, contingencia y riesgo. Barcelona: Anthropos, 1995.

GOLDSMITH, E. A blue print for survival. London: Penguin, 1972.

GONZALEZ-GAUDIANO, E. Educación para la ciudadanía ambiental. Interciencia, Caracas, v. 28, n. 10, p. 611-615, 2003.

GUERASIMOV, I. La sociedad y el medio natural. Moscú: Mir, 1983.

GUIMELLI, C. La función de enfermera: prácticas y representaciones sociales. In: ABRIC, J. C. Prácticas sociales y representaciones. México: Ediciones Coyoacán, 2001. p. 75-96.

KENNEDY, J. F. Convocation of the United Negro College Fund. Indianapolis: John F. Kennedy Presidential Library and Museum, 1959. Disponible en: < http://www.jfklibrary. org/Asset-Viewer/To6xnVCeNUSecmWECy7Fpw.aspx>. Visitado el: 25 sep. 2014.

LEAKEY, R.; LEWIN, R. La sexta extinción: el futuro de la vida y de la humanidad. Barcelona: Tusquets, 1997.

LEFF, E. Complejidad, racionalidad ambiental y diálogo de saberes: hacia una pedagogía ambiental. Desenvolvimento e meio ambiente, Curitiba, n. 16, p. 11-19, 2007. Disponible en: <http://ojs.c3sl.ufpr.br/ojs/index.php/made/article/viewFile/11901/8397>. Visitado el: 21 mar. 2016.

Discursos sustentables. 2. ed. México: Siglo XXI, 2010.

XXI, 2004.

Racionalidad ambiental: la reapropiación social de la naturaleza. México: Siglo

Saber ambiental. México: Siglo XXI, 2002.

Saber ambiental: sustentabilidade, racionalidade, complexidade e poder. 4. ed.

Petrópolis: Vozes, 2005.

LEZAMA, J. L. La construcción social y política del medio ambiente. México: El Colegio de México, 2004.

LIPOVETSKY, G. La era del vacío. Barcelona: Anagrama, 2000.

MARTÍNEZ ALIER, J. El ecologismo de los pobres: conflictos ambientales y lenguajes de valoración. Barcelona: Icaria, 2005.

MOSCOVICI, S. El psicoanálisis: su imagen y su público. Buenos Aires: Heumul, 1979.

NOGUERA, A. P. E1 reencantamiento del mundo. México: Programa de las Naciones Unidas para el Medio Ambiente; [Bogotá]: Universidad Nacional de Colombia, 2004.

Disponible en: <http://www.bdigital.unal.edu.co/5963/2/9687913312.pdf>. Visitado el: 21 mar. 2016. 
PÉREZ, M.; PORRAS, Y.; GONZÁLEZ, R. Identificación de las representaciones de ambiente y educación ambiental que circulan en la escuela. Tecné, Episteme y Didaxis, Bogotá, v. 21, p. 24-44. 2007. Disponible en: <https://dialnet.unirioja.es/servlet/ articulo?codigo $=3877547>$. Visitado el: 8 sep. 2015.

PÉREZ, M.; PORRAS Y.; GUZMÁN, H. Representaciones sociales de la educación ambiental y del campus universitario: una mirada de los docentes en formación de la UPN. Tecné, Episteme y Didaxis, Bogotá, n. 34, p. 47-69, 2013. Disponible en: <http://www. scielo.org.co/pdf/ted/n34/n34a04.pdf>. Visitado el: 5 sep. 2014.

PÉREZ, M. et al. Estudio para la identificación de tendencias en educación ambiental en Bogotá. Nodos y Nudos, Bogotá, v. 3, n. 22, p. 94-107, 2007. Disponible en: <http://www. scielo.org.co/pdf/ted/n34/n34a04.pdf>. Visitado el: 12 ago. 2015.

PEREZ, R.; PORRAS, Y. La complejidad en el marco de una propuesta pluriparadigmática. Tecné, Episteme y Didaxis, Bogotá, v. 17, p.104-116, 2005. Disponible en: <https:// dialnet.unirioja.es/servlet/articulo?codigo=3872075>. Visitado el: 21 mar. 2016.

PORRAS, Y. El aprendizaje significativo de los conceptos calor, temperatura y energía interna, una concreción de la propuesta de aprendizaje de la química como investigación orientada. 2005. Tesis (Maestría en Docencia de la Química) - Universidad Pedagógica Nacional, Bogotá, 2005.

. La construcción social de la crisis ambiental: reflexiones sobre el cambio climático desde una perspectiva crítica. In: PORRAS, Y. et al. Retos y oportunidades de la educación ambiental en el siglo XXI. Bogotá: Fondo Editorial Universidad Pedagógica Nacional, 2014a. p. 99-129.

Retos y oportunidades de la educación ambiental en el siglo XXI. In: PORRAS, Y. et al. Retos y oportunidades de la educación ambiental en el siglo XXI. Bogotá: Fondo Editorial Universidad Pedagógica Nacional, 2014b. p. 14-45.

RAUP, D. Extinction: bad genes or bad luck? New York: Norton, 1991.

SAUVÉ, L. Educación ambiental y ecociudadania: dimensiones claves de un proyecto político-pedagógico. Revista Científica, Bogotá, n. 18, p. 12-23, 2014. Disponible en: $<$ http:/ / revistas.udistrital.edu.co/ojs/index.php/revcie/article/view/5558/7072>. Visitado el: 10 sep. 2014.

SCHLOSBERG, D. Theorising environmental justice: the expanding sphere of a discourse. Environmental Politics, Abingdon, v. 22, n. 1, p. 37-55, 2013.

SCHUMACHER, E. F. Small is beautiful: a study of economics as if people mattered. New York: Harper \& Row, 1973. 
TOMASSINO, H.; FOLADORI, G.; TAKS, J. La crisis ambiental contemporánea. In: FOLADORI, G.; PIERRI, N. (Comp.). ¿Sustentabilidad?: desacuerdos sobre el desarrollo sustentable. México: Universidad Autónoma de Zacatecas, 2005. p. 9-26.

VERGÈS, P. L'évocation de l'argent: une méthode pour la définition du noyau central de la représentation. Bulletin de Psychologie, Paris, v. 45, n. 405, p. 203-209, 1992.

WALKER, G.; BULKELEY, H. Geographies of environmental justice. Geoforum, Kidlington, v. 37, n. 5, p. 655-659, 2006. 